\title{
Optimization of process parameter variations on leakage current in in silicon-on- insulator vertical double gate mosfet device
}

\author{
K.E. Kaharudin*, F. Salehuddin, A.S.M. Zain and M.N.I. Abd Aziz \\ Centre for Telecommunication Research and Innovation, \\ Faculty of Electronics and Computer Engineering, \\ Universiti Teknikal Malaysia Melaka (UTeM), \\ Hang Tuah Jaya, Durian Tunggal, 76100 Melaka, \\ *Email: khairilezwan@yahoo.com.my \\ Phone: +6094246239; Fax: +6094246222
}

\begin{abstract}
This paper presents a study of optimizing input process parameters on leakage current (I $\mathrm{IFF}_{\mathrm{F}}$ ) in silicon-on-insulator (SOI) Vertical Double-Gate [1] Metal Oxide Field-EffectTransistor (MOSFET) by using L36 Taguchi method. The performance of SOI Vertical DG-MOSFET device is evaluated in terms of its lowest leakage current (IOFF) value. An orthogonal array [2], main effects, signal-to-noise ratio (SNR) and analysis of variance (ANOVA) are utilized in order to analyze the effect of input process parameter variation on leakage current $\left(\mathrm{I}_{\mathrm{OFF}}\right)$. Based on the results, the minimum leakage current $\left(\left(\mathrm{I}_{\mathrm{OFF}}\right)\right.$ of SOI Vertical DG-MOSFET is observed to be $0.009 \mathrm{nA} / \mu \mathrm{m}$ or $9 \rho \mathrm{A} / \mu \mathrm{m}$ while keeping the drive current $\left(\mathrm{I}_{\mathrm{ON}}\right)$ value at $434 \mu \mathrm{A} / \mu \mathrm{m}$. Both the drive current $\left(\mathrm{I}_{\mathrm{ON}}\right)$ and leakage current $\left(\mathrm{I}_{\mathrm{OFF}}\right)$ values yield a higher $\mathrm{I}_{\mathrm{ON}} / \mathrm{I}_{\mathrm{OFF}}$ ratio $\left(48.22 \times 10^{6}\right)$ for low power consumption application. Meanwhile, polysilicon doping tilt angle and polysilicon doping energy are recognized as the most dominant factors with each of the contributing factor effects percentage of $59 \%$ and $25 \%$.
\end{abstract}

Keywords: Analysis of variance; DG-MOSFET; SNR; SOI.

\section{INTRODUCTION}

The Metal Oxide Semiconductor Field-Effect-Transistor (MOSFET) with silicon-oninsulator (SOI) technology has been widely studied due to its superb device performance. The SOI technology has been proven to suppress short channel effects (SCE), thus improving the drive current $\left(\mathrm{I}_{\mathrm{ON}}\right)$. The drive current $\left(\mathrm{I}_{\mathrm{ON}}\right)$ is an important response to determine the driving capability of the MOSFET device. However, the leakage current (I $\left.\mathrm{I}_{\mathrm{OFF}}\right)$ is still an important response to be controlled in order to obtain higher $\mathrm{I}_{\mathrm{ON}} / \mathrm{I}_{\mathrm{OFF}}$ ratio. The high IoN/IOFF ratio will lead to lower power consumption of the device. Therefore, in pursuing excellent characteristics of SOI vertical DG-MOSFET device, the drive current (ION) must be ensured to be large while keeping the leakage current (I $\mathrm{IFF}_{\mathrm{OF}}$ ) as low as possible. Leakage current (IOFF) is measured during the switch-off condition of the device. In other words, it is a value of drain current $\left(\mathrm{I}_{\mathrm{D}}\right)$ when there is no gate voltage $\left(\mathrm{V}_{\mathrm{G}}\right)$ applied [3]. Normally, as the device shrinks, the leakage current $\left(\mathrm{I}_{\mathrm{OFF}}\right)$ will be higher. High leakage current $\left(\mathrm{I}_{\mathrm{OFF}}\right)$ in nano-scale regimes is becoming a significant contributor to power dissipation of the MOSFET device [4]. This increase in IOFF is typically due to charge sharing effect caused by drain-induced barrier lowering (DIBL) or due to deep channel punchthrough currents [5]. As the channel width decreases, both threshold 
voltage $\left(\mathrm{V}_{\mathrm{TH}}\right)$ and leakage current ( $\left.\mathrm{I}_{\mathrm{OFF}}\right)$ will get modulated by the width of the transistor, giving rise to significant narrow-width effect. All these adverse effects will cause threshold voltage $\left(\mathrm{V}_{\mathrm{TH}}\right)$ reduction (leakage current increase), especially in very small scaled devices [4]. Many factors are believed to have a large contribution to a rise of leakage current (I $\mathrm{IFF}_{\mathrm{OF}}$ ) value. One of the most recognized factors is known as process parameter variations. The input process parameters, such as $\mathrm{V}_{\mathrm{TH}}$ implant dose, $\mathrm{V}_{\mathrm{TH}}$ implant energy, polysilicon tilt angle, S/D implant energy and etcetera, need to be optimized in order to obtain a robust design. A lot of input process parameters have to be studied in order to identify the most significant factors that are influencing the leakage current ( $\left.\mathrm{I}_{\mathrm{OFF}}\right)$ value. This paper attempts to describe the optimization of input process parameters for a minimum value of leakage current $\left(\mathrm{I}_{\mathrm{OFF}}\right)$ in the SOI Vertical DGMOSFET device. The responses of certain designs can be optimized by modeling the input process parameters [4, 6-9]. Sixteen input process parameters are involved in the analysis, which are substrate implant dose, $\mathrm{V}_{\mathrm{TH}}$ implant dose, $\mathrm{V}_{\mathrm{TH}}$ implant energy, $\mathrm{V}_{\mathrm{TH}}$ implant tilt, polysilicon doping dose, polysilicon doping energy, polysilicon doping tilt, halo implant dose, halo implant energy, halo implant tilt, S/D implant dose, S/D implant energy, S/D implant tilt, compensation implant dose, compensation implant energy and compensation implant tilt. Due to its large number of input process parameters, an orthogonal array of $\mathrm{L}_{36}$ is selected for this analysis.

The well-known statistical method known as Taguchi method is utilized in this analysis. The Taguchi approach provides a practical design strategy in which a modified design of experiment (DOE) is introduced. This technique emphasizes on reducing the number of experimental runs, but still increasing the efficiency. In the present study, there are mixed matrices of 16 input process parameters with 3 levels and 2 noise factors with 2 levels involved. There will be as many as $172,186,884(316 \times 22)$ runs of experiment if using the conventional full factorial design. The experiment will take only 144 runs with Taguchi method. Therefore, Taguchi method is capable of assisting designer to study the effect of many factors in the most economical way. A special orthogonal array consisting of 36 rows and 4 columns is constructed in order to retrieve 144 samples of result. This orthogonal array is used for design of experiment (DOE) that could assist the designer to study multiple process parameters variation in a fast and economic way. Signal-to-noise ratio (SNR) is utilized in order to analyze the data and then to figure out the optimal combination of process parameters [10]. There are three categories of performance characteristics in the analysis of SNR, which are known as nominal-the-better, lower-thebetter and higher-the-better [11]. The SNR of each level of input process parameters is computed based on signal-to-noise $(\mathrm{S} / \mathrm{N})$ analysis. Regardless of the category of the performance characteristic, larger SNR corresponds to better performance characteristic $[12,13]$.

Therefore, the optimal level of the process parameters is the level with the highest SNR. In addition, a statistical analysis of variance (ANOVA) is conducted to observe which process parameters are statistically dominant and significant. With the SNR and ANOVA analysis, the optimal combination of the process parameters can be accurately predicted $[14,15]$. Finally, a confirmation experiment is performed to verify the optimal process parameters obtained from the Taguchi analysis. Therefore, the Taguchi method is utilized to obtain the most optimal process parameters for lower I $I_{\mathrm{OFF}}$ value of the device. 


\section{MATERIALS AND METHODS}

SILVACO Technology Computer Aided Design (TCAD) tools are utilized to aid in designing and optimizing the input process parameters. SILVACO TCAD tools consist of two modules, which are ATHENA and ATLAS. ATHENA module was used for process simulation in the device's design. Meanwhile, ATLAS module was used for device simulation and characterization.

\section{Process and Device Structure}

The process began with a selection of a P-type silicon with $<100>$ orientation as the main substrate. Initial silicon was then being doped with boron with concentration of $1 \times 10^{14}$ atom $/ \mathrm{cm}^{3}$. The formation of BOX was done by depositing $40 \mathrm{~nm}$ oxide thickness ( $\left.\mathrm{t}_{\mathrm{BOX}}\right)$. The silicon thickness [16] was about $4 \mathrm{~nm}$. The silicon was dry etched in order to form a pillar or ridge that separates the two gates. The height of the silicon pillar of $140 \mathrm{~nm}$ was preferred in order to provide the effective channel length $\left(\mathrm{L}_{\mathrm{eff}}\right)$ of $79 \mathrm{~nm}$. The simulation process was followed by the gate oxidation process at a temperature of $875^{\circ} \mathrm{C}$. The thickness of gate oxide is a very essential parameter in vertical dimension, which will determine the gate control. Next step was to dope substrate ions which was boron into the silicon with concentration of $3.81 \times 10^{11}$ atom $/ \mathrm{cm}^{3}$ at an energy level of $10 \mathrm{Kev}$ and tilt angle of $7^{\circ}$. This step is important in order to vary the threshold voltage $\left(\mathrm{V}_{\mathrm{TH}}\right)$ of the vertical DG-MOSFET device. The next simulation process was to deposit polysilicon on top of the gate oxide. Then, the polysilicon and polysilicon oxide were etched away to form a gate polysilicon. The gate was made of polysilicon due to its ability to prevent source/drain ions from being penetrated into channel region. A layer of oxide was oxidized on top of polysilicon deposition at a temperature of $880 \mathrm{C}^{\circ}$. A phosphor dosage of $1 \times 10^{18}$ atom $/ \mathrm{cm}^{3}$ was then dipped into the polysilicon gate at an energy level of 20 Kev and tilt angle of $10^{\circ}$. This is done in order to increase the conductivity of the polysilicon since polysilicon is a low conductive metal. The conductivity of the gate would affect the switching frequency of the transistor.

In order to get an optimum performance for Vertical DG-MOSFET device, indium with a dosage of $1.17 \times 10^{13}$ atom $/ \mathrm{cm}^{3}$ was doped at an energy level of $170 \mathrm{Kev}$ and tilt angle of $24^{\circ}$. Halo implantation was followed by depositing sidewall spacers. The sidewall spacers were then used as a mask for source/drain implantation. An arsenic atom with a concentration of $1.25 \times 10^{18}$ atom $/ \mathrm{cm}^{3}$ at an energy level of $45 \mathrm{Kev}$ and tilt angle of $80^{\circ}$ was implanted to ensure the smooth current flow in vertical DG-MOSFET device. Compensation implantation is utilized later by implanting phosphor dosage of $2.51 \times 10^{12}$ atom $/ \mathrm{cm}^{3}$ at an energy level of $63 \mathrm{Kev}$ and tilt angle of $7^{\circ}$. This step is taken in order to reduce parasitic effects that could lower the current. Next, silicide (CoSi) was formed at the top of the source and drain region by sputtering cobalt on silicon surface. This transistor was then connected with aluminum metal. The aluminum layer was deposited on the top of the Intel-Metal Dielectric (IMD) and unwanted aluminum was etched to develop the contacts [17-21]. The procedure was completed after the metallization and etching were performed for the electrode formation, and the bonding pads were opened. It is important to use the same level of process parameters for both SOI and without SOI vertical DG-MOSFET device in order to investigate their performance. The final SOI vertical DG-MOSFET device structure was completed by mirroring the right-hand side structure. The completed structure of SOI Vertical DG-MOSFET device is illustrated in Figure 1. Once the devices were built with ATHENA, the complete devices can be simulated in ATLAS to provide specific characteristics such as the subthreshold drain 
current $\left(\mathrm{I}_{\mathrm{D}}\right)$ versus gate voltage $\left(\mathrm{V}_{\mathrm{G}}\right)$. The off-state leakage current ( $\left.\mathrm{I}_{\mathrm{OFF}}\right)$ can be extracted from that curve.

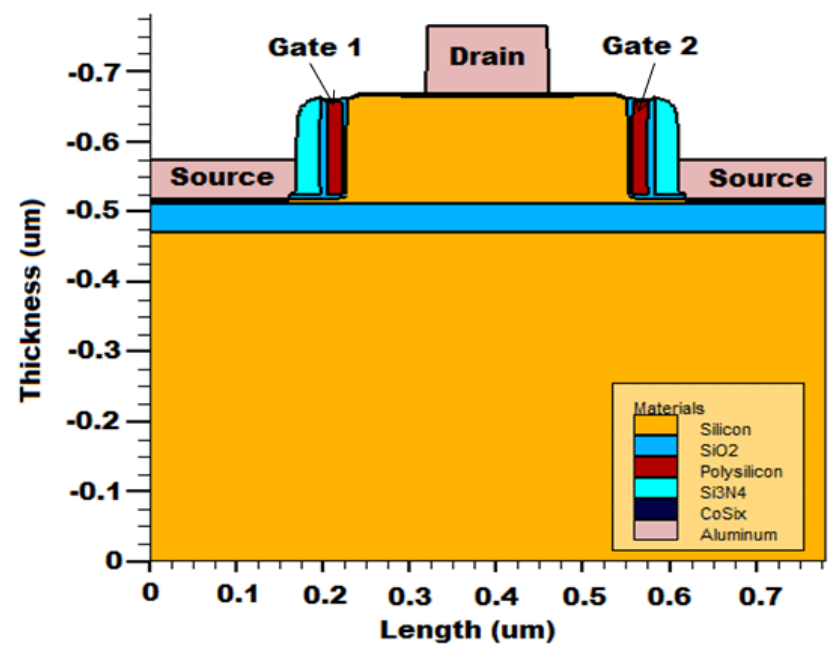

Figure 1. SOI vertical DG-MOSFET device structure.

Table 1. Input process parameters and their levels.

\begin{tabular}{|c|c|c|c|c|c|}
\hline Symbol & Process Parameter & Units & Level 1 & Level 2 & Level 3 \\
\hline A & Substrate Implant Dose & atom $/ \mathrm{cm}^{3}$ & 1E14 & $1.03 \mathrm{E} 14$ & - \\
\hline B & $\mathrm{V}_{\mathrm{TH}}$ Implant Dose & atom $/ \mathrm{cm}^{3}$ & $3.78 \mathrm{E} 11$ & $3.81 \mathrm{E} 11$ & - \\
\hline $\mathrm{C}$ & $\mathrm{V}_{\mathrm{TH}}$ Implant Energy & kev & 10 & 12 & - \\
\hline $\mathrm{D}$ & $\mathrm{V}_{\mathrm{TH}}$ Implant Tilt & degree & 7 & 10 & 13 \\
\hline $\mathrm{E}$ & Polysilicon Doping Dose & atom $/ \mathrm{cm}^{3}$ & $3.60 \mathrm{E} 14$ & $3.63 \mathrm{E} 14$ & $3.66 \mathrm{E} 14$ \\
\hline $\mathrm{F}$ & Polysilicon Doping Energy & kev & 20 & 22 & 24 \\
\hline G & Polysilicon Doping Tilt & degree & 7 & 10 & 13 \\
\hline $\mathrm{H}$ & Halo Implant Dose & atom $/ \mathrm{cm}^{3}$ & $1.17 \mathrm{E} 13$ & $1.20 \mathrm{E} 13$ & $1.23 \mathrm{E} 13$ \\
\hline $\mathrm{J}$ & Halo Implant Energy & kev & 170 & 172 & 174 \\
\hline $\mathrm{K}$ & Halo Implant Tilt & degree & 24 & 27 & 30 \\
\hline $\mathrm{L}$ & S/D Implant Dose & atom $/ \mathrm{cm}^{3}$ & $1.22 \mathrm{E} 18$ & $1.25 \mathrm{E} 18$ & $1.28 \mathrm{E} 18$ \\
\hline M & S/D Implant Energy & kev & 43 & 45 & 47 \\
\hline $\mathrm{N}$ & S/D Implant Tilt & degree & 74 & 77 & 80 \\
\hline $\mathrm{O}$ & Compensate Implant Dose & atom $/ \mathrm{cm}^{3}$ & $2.51 \mathrm{E} 12$ & $2.54 \mathrm{E} 12$ & $2.57 \mathrm{E} 12$ \\
\hline $\mathrm{P}$ & Compensate Implant Energy & kev & 61 & 63 & 65 \\
\hline Q & Compensate Implant Tilt & degree & 7 & 10 & 13 \\
\hline
\end{tabular}

\section{Taguchi Orthogonal L36 Array Design}

The objective of the present study was to determine the optimal level of 16 input process parameters, i.e. substrate implant dose, $\mathrm{V}_{\mathrm{TH}}$ implant dose, $\mathrm{V}_{\mathrm{TH}}$ implant energy, $\mathrm{V}_{\mathrm{TH}}$ implant tilt, polysilicon doping dose, polysilicon doping tilt, halo implant dose, halo implant tilt, S/D implant dose and etc. Each of them were represented by A, B, C, D, E, F, G, H, J, K, L, M, N, O, P and Q. Two levels of the first 3 input process parameters and three levels of the other 13 input process parameters were selected as shown in Table 1. The presence of two noise factors, gate oxidation temperature and polysilicon oxidation temperature, were meant to put the undesirable effect (temperature) into design consideration. The values of noise factors at different levels are listed in Table 2.The 
function of an orthogonal array is to reduce the number of experiments in identifying the most dominant factors in the design. The data produced from the experiment will be studied by using the $\mathrm{S} / \mathrm{N}$ and ANOVA analysis. $\mathrm{L}_{36}\left(3^{16}\right)$ orthogonal array consists of 36 sets of experiment. The experimental layout of $\mathrm{L}_{36}\left(3^{16}\right)$ orthogonal array for the input process parameters is shown in Table 3.

Table 2. Noise Factors and Their Levels

\begin{tabular}{lcccc}
\hline Symbol & Noise factor & Units & Level 1 & Level 2 \\
\hline $\mathrm{U}$ & Gate Oxidation Temperature & $\mathrm{C}^{\mathrm{o}}$ & 875 & 878 \\
$\mathrm{~V}$ & Polysilicon Oxidation Temperature & $\mathrm{C}^{\mathrm{o}}$ & 877 & 880 \\
\hline
\end{tabular}

Table 3. Experimental Layout using $\mathrm{L}_{36}$ Orthogonal Array

\begin{tabular}{|c|c|c|c|c|c|c|c|c|c|c|c|c|c|c|c|c|}
\hline \multirow[t]{2}{*}{ Exp no. } & \multicolumn{16}{|c|}{ Process Parameter Levels } \\
\hline & A & B & $\mathrm{C}$ & $\mathrm{D}$ & $\mathrm{E}$ & $\mathrm{F}$ & $\mathrm{G}$ & $\mathrm{H}$ & $\mathrm{J}$ & $\mathrm{K}$ & $\mathrm{L}$ & $\mathrm{M}$ & $\mathrm{N}$ & $\mathrm{O}$ & $\mathrm{P}$ & $\mathrm{Q}$ \\
\hline 1 & 1 & 1 & 1 & 1 & 1 & 1 & 1 & 1 & 1 & 1 & 1 & 1 & 1 & 1 & 1 & 1 \\
\hline 2 & 1 & 1 & 1 & 1 & 2 & 2 & 2 & 2 & 2 & 2 & 2 & 2 & 2 & 2 & 2 & 2 \\
\hline 3 & 1 & 1 & 1 & 1 & 3 & 3 & 3 & 3 & 3 & 3 & 3 & 3 & 3 & 3 & 3 & 3 \\
\hline 4 & 1 & 2 & 2 & 1 & 1 & 1 & 1 & 1 & 2 & 2 & 2 & 2 & 3 & 3 & 3 & 3 \\
\hline 5 & 1 & 2 & 2 & 1 & 2 & 2 & 2 & 2 & 3 & 3 & 3 & 3 & 1 & 1 & 1 & 1 \\
\hline 6 & 1 & 2 & 2 & 1 & 3 & 3 & 3 & 3 & 1 & 1 & 1 & 1 & 2 & 2 & 2 & 2 \\
\hline 7 & 2 & 1 & 2 & 1 & 1 & 1 & 2 & 3 & 1 & 2 & 3 & 3 & 1 & 2 & 2 & 3 \\
\hline 8 & 2 & 1 & 2 & 1 & 2 & 2 & 3 & 1 & 2 & 3 & 1 & 1 & 2 & 3 & 3 & 1 \\
\hline 9 & 2 & 1 & 2 & 1 & 3 & 3 & 1 & 2 & 3 & 1 & 2 & 2 & 3 & 1 & 1 & 2 \\
\hline 10 & 2 & 2 & 1 & 1 & 1 & 1 & 3 & 2 & 1 & 3 & 2 & 3 & 2 & 1 & 3 & 2 \\
\hline 11 & 2 & 2 & 1 & 1 & 2 & 2 & 1 & 3 & 2 & 1 & 3 & 1 & 3 & 2 & 1 & 3 \\
\hline 12 & 2 & 2 & 1 & 1 & 3 & 3 & 2 & 1 & 3 & 2 & 1 & 2 & 1 & 3 & 2 & 1 \\
\hline 13 & 1 & 1 & 1 & 2 & 1 & 2 & 3 & 1 & 3 & 2 & 1 & 3 & 3 & 2 & 1 & 2 \\
\hline 14 & 1 & 1 & 1 & 2 & 2 & 3 & 1 & 2 & 1 & 3 & 2 & 1 & 1 & 3 & 2 & 3 \\
\hline 15 & 1 & 1 & 1 & 2 & 3 & 1 & 2 & 3 & 2 & 1 & 3 & 2 & 2 & 1 & 3 & 1 \\
\hline 16 & 1 & 2 & 2 & 2 & 1 & 2 & 3 & 2 & 1 & 1 & 3 & 2 & 3 & 3 & 2 & 1 \\
\hline 17 & 1 & 2 & 2 & 2 & 2 & 3 & 1 & 3 & 2 & 2 & 1 & 3 & 1 & 1 & 3 & 2 \\
\hline 18 & 1 & 2 & 2 & 2 & 3 & 1 & 2 & 1 & 3 & 3 & 2 & 1 & 2 & 2 & 1 & 3 \\
\hline 19 & 2 & 1 & 2 & 2 & 1 & 2 & 1 & 3 & 3 & 3 & 1 & 2 & 2 & 1 & 2 & 3 \\
\hline 20 & 2 & 1 & 2 & 2 & 2 & 3 & 2 & 1 & 1 & 1 & 2 & 3 & 3 & 2 & 3 & 1 \\
\hline 21 & 2 & 1 & 2 & 2 & 3 & 1 & 3 & 2 & 2 & 2 & 3 & 1 & 1 & 3 & 1 & 2 \\
\hline 22 & 2 & 2 & 1 & 2 & 1 & 2 & 2 & 3 & 3 & 1 & 2 & 1 & 1 & 3 & 3 & 2 \\
\hline 23 & 2 & 2 & 1 & 2 & 2 & 3 & 3 & 1 & 1 & 2 & 3 & 2 & 2 & 1 & 1 & 3 \\
\hline 24 & 2 & 2 & 1 & 2 & 3 & 1 & 1 & 2 & 2 & 3 & 1 & 3 & 3 & 2 & 2 & 1 \\
\hline 25 & 1 & 1 & 1 & 3 & 1 & 3 & 2 & 1 & 2 & 3 & 3 & 1 & 3 & 1 & 2 & 2 \\
\hline 26 & 1 & 1 & 1 & 3 & 2 & 1 & 3 & 2 & 3 & 1 & 1 & 2 & 1 & 2 & 3 & 3 \\
\hline 27 & 1 & 1 & 1 & 3 & 3 & 2 & 1 & 3 & 1 & 2 & 2 & 3 & 2 & 3 & 1 & 1 \\
\hline 28 & 1 & 2 & 2 & 3 & 1 & 3 & 2 & 2 & 2 & 1 & 1 & 3 & 2 & 3 & 1 & 3 \\
\hline 29 & 1 & 2 & 2 & 3 & 2 & 1 & 3 & 3 & 3 & 2 & 2 & 1 & 3 & 1 & 2 & 1 \\
\hline 30 & 1 & 2 & 2 & 3 & 3 & 2 & 1 & 1 & 1 & 3 & 3 & 2 & 1 & 2 & 3 & 2 \\
\hline 31 & 2 & 1 & 2 & 3 & 1 & 3 & 3 & 3 & 2 & 3 & 2 & 2 & 1 & 2 & 1 & 1 \\
\hline 32 & 2 & 1 & 2 & 3 & 2 & 1 & 1 & 1 & 3 & 1 & 3 & 3 & 2 & 3 & 2 & 2 \\
\hline 33 & 2 & 1 & 2 & 3 & 3 & 2 & 2 & 2 & 1 & 2 & 1 & 1 & 3 & 1 & 3 & 3 \\
\hline 34 & 2 & 2 & 1 & 3 & 1 & 3 & 1 & 2 & 3 & 2 & 3 & 1 & 2 & 2 & 3 & 1 \\
\hline 35 & 2 & 2 & 1 & 3 & 2 & 1 & 2 & 3 & 1 & 3 & 1 & 2 & 3 & 3 & 1 & 2 \\
\hline 36 & 2 & 2 & 1 & 3 & 3 & 2 & 3 & 1 & 2 & 1 & 2 & 3 & 1 & 1 & 2 & 3 \\
\hline
\end{tabular}




\section{RESULTS AND DISCUSSION}

After the process simulation was done by using ATHENA module, the designed device was then characterized by utilizing ATLAS module. In this section, the electrical characteristics of the first set of experiments will be discussed. Finally, the optimization approach using Taguchi method is discussed in detail.

\section{Device Characterization}

Figure 2 shows the graph of the subthreshold drain current $\left(\mathrm{I}_{\mathrm{D}}\right)$ versus gate voltage $\left(\mathrm{V}_{\mathrm{G}}\right)$ at drain voltage $\mathrm{V}_{\mathrm{D}}=0.05 \mathrm{~V}$ and $\mathrm{V}_{\mathrm{D}}=1.0 \mathrm{~V}$ for SOI vertical DG-MOSFET device. The value of off-leakage current $\left(\mathrm{I}_{\mathrm{OFF}}\right)$ and drive current $\left(\mathrm{I}_{\mathrm{ON}}\right)$ can be extracted from the graph. From the graph, it was observed that the value of drive current $\left(\mathrm{I}_{\mathrm{ON}}\right)$ was at $474 \mu \mathrm{A} / \mu \mathrm{m}$. The high drive current $\left(\mathrm{I}_{\mathrm{ON}}\right)$ is required for high speed switching operation. The $\mathrm{I}_{\mathrm{ON}}$ is the maximum drain current (IDMAX) when $\mathrm{V}_{\mathrm{GS}}=\mathrm{V}_{\mathrm{DD}}$ and $\mathrm{V}_{\mathrm{DS}}=\mathrm{V}_{\mathrm{DD}}$. Meanwhile, the offleakage current (IOFF) was observed to be at $0.024 \times 10^{-9} \mathrm{~A} / \mu \mathrm{m}$. The IofF is defined as a drain to source current and it is measured when $V_{G S}=0$ and $V_{D S}=V_{D D}$. In other words, the off-state current (IOFF) is the drain current when no gate voltage is applied. The offleakage current (IOFF) was the electrical characteristic that had been optimized by using Taguchi method.

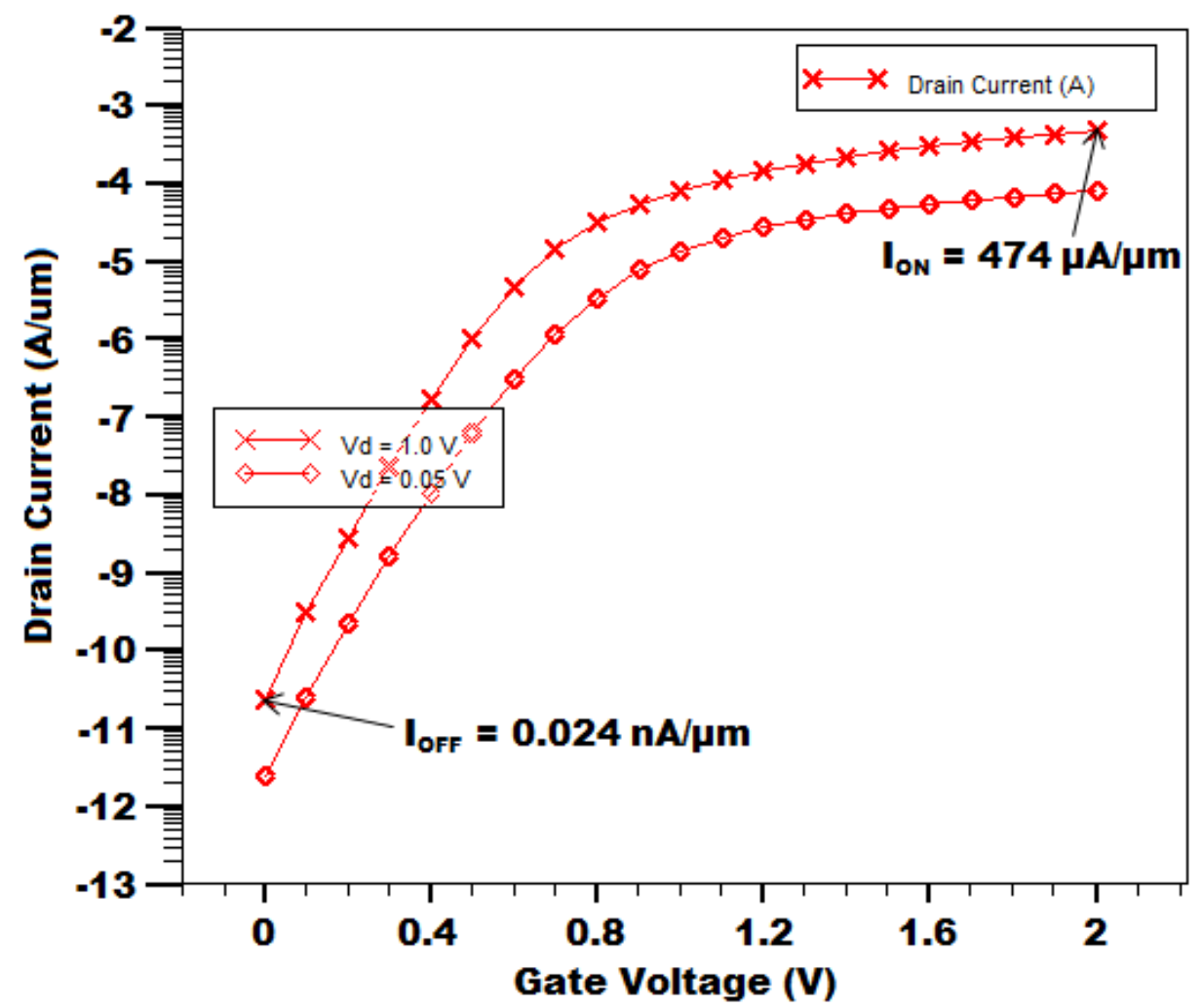

Figure 2. Graph of subthreshold drain current $\left(\mathrm{I}_{\mathrm{D}}\right)$ versus gate voltage $\left(\mathrm{V}_{\mathrm{G}}\right)$

\section{Leakage Current (IofF) Acquisition}

The experimental results for IOFF in SOI Vertical DG-MOSFET device are shown in Table 4. Each set of experiment produced four different Ioff values due to the presence of two noise factors, which are factor $\mathrm{U}$ (Gate Oxidation Temperature) and factor $\mathrm{V}$ (Polysilicon Oxidation Temperature). 
Table 4. Ioff values for SOI vertical DG-MOSFET device.

\begin{tabular}{|c|c|c|c|c|}
\hline \multirow{2}{*}{$\begin{array}{l}\text { Experiment } \\
\text { no. }\end{array}$} & \multicolumn{4}{|c|}{ Leakage Current, I IFF $(\mathrm{nA} / \mu \mathrm{m})$} \\
\hline & $\begin{array}{c}\text { IOFF1 } \\
\left(\mathrm{U}_{1} \mathrm{~V}_{1}\right)\end{array}$ & $\begin{array}{c}\text { IoFF2 } \\
\left(\mathrm{U}_{1} \mathrm{~V}_{2}\right)\end{array}$ & $\begin{array}{c}\text { IoFF3 } \\
\left(\mathrm{U}_{2} \mathrm{~V}_{1}\right)\end{array}$ & $\begin{array}{c}\text { IoFF4 } \\
\left(\mathrm{U}_{2} \mathrm{~V}_{2}\right)\end{array}$ \\
\hline 1 & 0.024 & 0.017 & 0.020 & 0.014 \\
\hline 2 & 12.965 & 9.108 & 11.027 & 7.49 \\
\hline 3 & 7799.56 & 5704.11 & 7202.73 & 5234.88 \\
\hline 4 & 0.027 & 0.020 & 0.022 & 0.016 \\
\hline 5 & 3.722 & 2.450 & 3.128 & 2.092 \\
\hline 6 & 7096.08 & 4826.54 & 6520.6 & 4349.59 \\
\hline 7 & 0.259 & 0.184 & 0.201 & 0.142 \\
\hline 8 & 1044.71 & 717.9 & 900.67 & 638.0 \\
\hline 9 & 1.298 & 0.775 & 1.073 & 0.662 \\
\hline 10 & 42.661 & 22.998 & 36.374 & 18.758 \\
\hline 11 & 0.070 & 0.045 & 0.057 & 0.037 \\
\hline 12 & 297.33 & 224.70 & 264.64 & 199.79 \\
\hline 13 & 576.65 & 425.39 & 507.22 & 372.93 \\
\hline 14 & 0.946 & 0.523 & 0.808 & 0.442 \\
\hline 15 & 0.253 & 0.148 & 0.192 & 0.111 \\
\hline 16 & 482.03 & 345.76 & 418.98 & 297.89 \\
\hline 17 & 1.234 & 0.728 & 1.041 & 0.615 \\
\hline 18 & 0.318 & 0.219 & 0.256 & 0.174 \\
\hline 19 & 0.029 & 0.022 & 0.025 & 0.019 \\
\hline 20 & 287.05 & 209.61 & 256.36 & 185.29 \\
\hline 21 & 22.985 & 12.753 & 18.763 & 10.234 \\
\hline 22 & 11.423 & 7.076 & 9.046 & 5.975 \\
\hline 23 & 8331.52 & 5985.85 & 7669.64 & 5480.76 \\
\hline 24 & 0.017 & 0.012 & 0.014 & 0.01 \\
\hline 25 & 298.31 & 220.02 & 261.72 & 197.37 \\
\hline 26 & 16.58 & 8.529 & 12.799 & 7.01 \\
\hline 27 & 0.052 & 0.04 & 0.045 & 0.035 \\
\hline 28 & 121.01 & 87.213 & 105.61 & 75.471 \\
\hline 29 & 12.506 & 6.758 & 9.985 & 5.313 \\
\hline 30 & 0.076 & 0.045 & 0.064 & 0.038 \\
\hline 31 & 6575.38 & 4703.25 & 5863.8 & 4307.13 \\
\hline 32 & 0.022 & 0.016 & 0.017 & 0.012 \\
\hline 33 & 20.504 & 13.763 & 17.33 & 11.519 \\
\hline 34 & 1.571 & 0.853 & 1.321 & 0.727 \\
\hline 35 & 0.22 & 0.15 & 0.177 & 0.117 \\
\hline 36 & 515.85 & 372.67 & 449.27 & 322.55 \\
\hline
\end{tabular}

Signal-to-noise (S/N) Response Analysis

After the results of 36 experiments have been obtained by utilizing SILVACO TCAD tools, the next step is to implement $\mathrm{S} / \mathrm{N}$ response analysis. The objective of the $\mathrm{S} / \mathrm{N}$ response analysis is to determine the signal-to-noise ratio (SNR) for every input process parameters. SNR is used to figure out the optimal input process parameters and analyze experimental data. For the S/N response analysis for IofF, category of the lower-the-better 
is selected due to its ability to reduce the response value as minimum as possible. The SNR (lower-the-better), $\eta$ can be expressed as [22]:

$$
\eta=-10 \log _{10}\left[\frac{1}{n} \sum_{i=1}^{n} y_{i}^{2}\right]
$$

where $n$ is the number of tests and $y i$ is the experimental values of IOFF. The $\mathrm{S} / \mathrm{N}$ ratio (lower-the-better) of each experiment was computed and recorded in Table 5 [22].

Table 5. Mean sum of SQ and $\mathrm{S} / \mathrm{N}$ ratio for $\mathrm{I}_{\mathrm{OFF}}$.

\begin{tabular}{lcc}
\hline Exp no. & Mean Sum of SQ & $\begin{array}{c}\text { S/N Ratio } \\
\text { (lower-the-better) [23] }\end{array}$ \\
\hline 1 & & 34.374 \\
2 & 0.0004 & -20.301 \\
3 & 107.19 & -76.351 \\
4 & $4 \mathrm{E}+07$ & 33.305 \\
5 & 0.0005 & -9.2963 \\
6 & 8.5042 & -75.286 \\
7 & $3 \mathrm{E}+07$ & 13.939 \\
8 & 0.0404 & -58.49 \\
9 & 706262 & 0.1379 \\
10 & 0.9688 & -30.026 \\
11 & 1005.9 & 25.397 \\
12 & 0.0029 & -47.939 \\
13 & 62211 & -53.569 \\
14 & 227458 & 2.9742 \\
15 & 0.5042 & 14.714 \\
16 & 0.0338 & -51.877 \\
17 & 154046 & 0.5618 \\
18 & 0.8787 & 12.131 \\
19 & 0.0612 & 32.383 \\
20 & 0.0006 & -47.528 \\
21 & 56597 & -24.578 \\
22 & 286.93 & -18.723 \\
23 & 74.521 & -76.86 \\
24 & $5 \mathrm{E}+07$ & 37.393 \\
25 & 0.0002 & -47.868 \\
26 & 61212 & -21.466 \\
27 & 140.15 & 27.239 \\
28 & 0.0019 & -39.901 \\
29 & 9774.7 & -19.165 \\
30 & 82.5 & 24.769 \\
31 & 0.0033 & -74.709 \\
32 & $3 \mathrm{E}+07$ & 35.328 \\
33 & 0.0003 & -24.162 \\
34 & 260.71 & -1.3587 \\
35 & 1.3673 & 15.379 \\
36 & 0.029 & -52.497 \\
\hline & 177717 & \\
& & \\
& &
\end{tabular}


The effect of each input process parameter on the $\mathrm{S} / \mathrm{N}$ ratio at different levels was separated because the experimental design is orthogonal. The $\mathrm{S} / \mathrm{N}$ ratio (SNR) for each of the process parameter is summarized in Table 6. Normally, a larger SNR will result in a lower value of leakage current $\left(\mathrm{I}_{\mathrm{OFF}}\right)$. The effect of each input process parameter on the $\mathrm{S} / \mathrm{N}$ ratio at different levels was separated because the experimental design is orthogonal. In addition, the overall mean SNR for the 36 experiments is also calculated and listed in Table 6 . Basically, the larger the $\mathrm{S} / \mathrm{N}$ ratio will result in better quality characteristic for leakage current [10]. The higher the quality characteristic value to the target, the better the device quality will be [12]. It is crucial that the effort must be focused on reducing sensitivity to noise by optimizing SNR.

Table 6. S/N response for IOFF.

\begin{tabular}{lcccc}
\hline Symbol & Process Parameter & \multicolumn{3}{c}{ S/N ratio (Lower-the-better) } \\
\cline { 2 - 4 } & & Level 1 & Level 2 & Level 3 \\
\hline A & Substrate Implant Dose & -14.72 & -16.5 & - \\
B & V TH Implant Dose $_{\text {TH }}$ & -16 & -15.22 & - \\
C & V $_{\text {TH Implant Energy }}$ & -16.08 & -15.14 & - \\
D & V TH Implant Tilt $_{\text {Polysilicon Doping Dose }}$ & -17.54 & -14.41 & -14.87 \\
E & -17 & -20.11 & -9.713 \\
F & Polysilicon Doping Energy & 2.7877 & -9.271 & -9.713 \\
G & Polysilicon Doping Tilt & 21.042 & -22.29 & -45.58 \\
H & Halo Implant Dose & -14.75 & -15.2 & -16.87 \\
J & Halo Implant Energy & -21.24 & -11.59 & -13.99 \\
K & Halo Implant Tilt & -10.79 & -16.07 & -19.97 \\
L & S/D Implant Dose & -22.38 & -9.94 & -14.5 \\
$\mathrm{M}$ & S/D Implant Energy & -16.23 & -20.03 & -10.57 \\
N & S/D Implant Tilt & -8.726 & -15.04 & -23.07 \\
$\mathrm{O}$ & Compensation Implant Dose & -9.152 & -15.05 & -22.63 \\
$\mathrm{P}$ & Compensation Implant Energy & -19.34 & -10.42 & -17.06 \\
$\mathrm{Q}$ & Compensation Implant Tilt & -16.39 & -21.84 & -8.603 \\
\hline
\end{tabular}

\section{Analysis of Variance (ANOVA)}

The objective of the analysis of variance (ANOVA) is to find out which input process parameters contributes the most significant impact on leakage current (IOFF). Basically, it computes parameters known as sum of squares (SS), degree of freedom (DF), variance, F-value and percentage of each factor. The results of ANOVA for the SOI Vertical DGMOSFET device are shown in Table 7. According to these analyses, the most dominant factors for SNR are factor G (Polysilicon doping tilt=59\%) and factor F (Polysilicon doping energy $=25 \%$ ). Therefore, these factors should be set at 'best setting'. Meanwhile, the remaining factors will be considered as neutral or negligible factors. Therefore, they do not contribute large effect on the output response. The neutral factors level can be adjusted if the leakage current (IOFF) value is not small as expected. The percentage of factor effect on SNR indicates the priority of a factor (process parameter) to reduce variation. The Pareto plot of standardized effect of Ioff for SOI Vertical DG-MOSFET device is shown in Figure 3. The Pareto plot compares the relative magnitude and the statistical significance of all the main effects and ranks of parameter accordingly. 
Table 7. Results of ANOVA for IOFF.

\begin{tabular}{lccccc}
\hline Process Parameters & DF & SS & MS & F-value & Factor effect on SNR (\%) \\
\hline A & 1 & 28 & 28 & 60 & 0 \\
B & 1 & 5 & 5 & 11 & 0 \\
C & 1 & 8 & 8 & 17 & 0 \\
D & 2 & 69 & 34 & 73 & 0 \\
E & 2 & 648 & 3421 & 722 & 1 \\
F & 2 & 11885 & 5943 & 12548 & 25 \\
G & 2 & 27436 & 13718 & 28966 & 59 \\
H & 2 & 30 & 15 & 32 & 0 \\
J & 2 & 606 & 303 & 640 & 1 \\
K & 2 & 509 & 255 & 538 & 1 \\
L & 2 & 951 & 475 & 1004 & 2.04 \\
M & 2 & 544 & 272 & 574 & 1 \\
N & 2 & 1240 & 620 & 1309 & 2 \\
O & 2 & 1095 & 547 & 1156 & 1 \\
P & 2 & 516 & 83 & 545 & 2 \\
Q & 2 & 1062 & 129 & 1121 & \\
\hline
\end{tabular}

\section{Factor Effect on SNR (\%)}

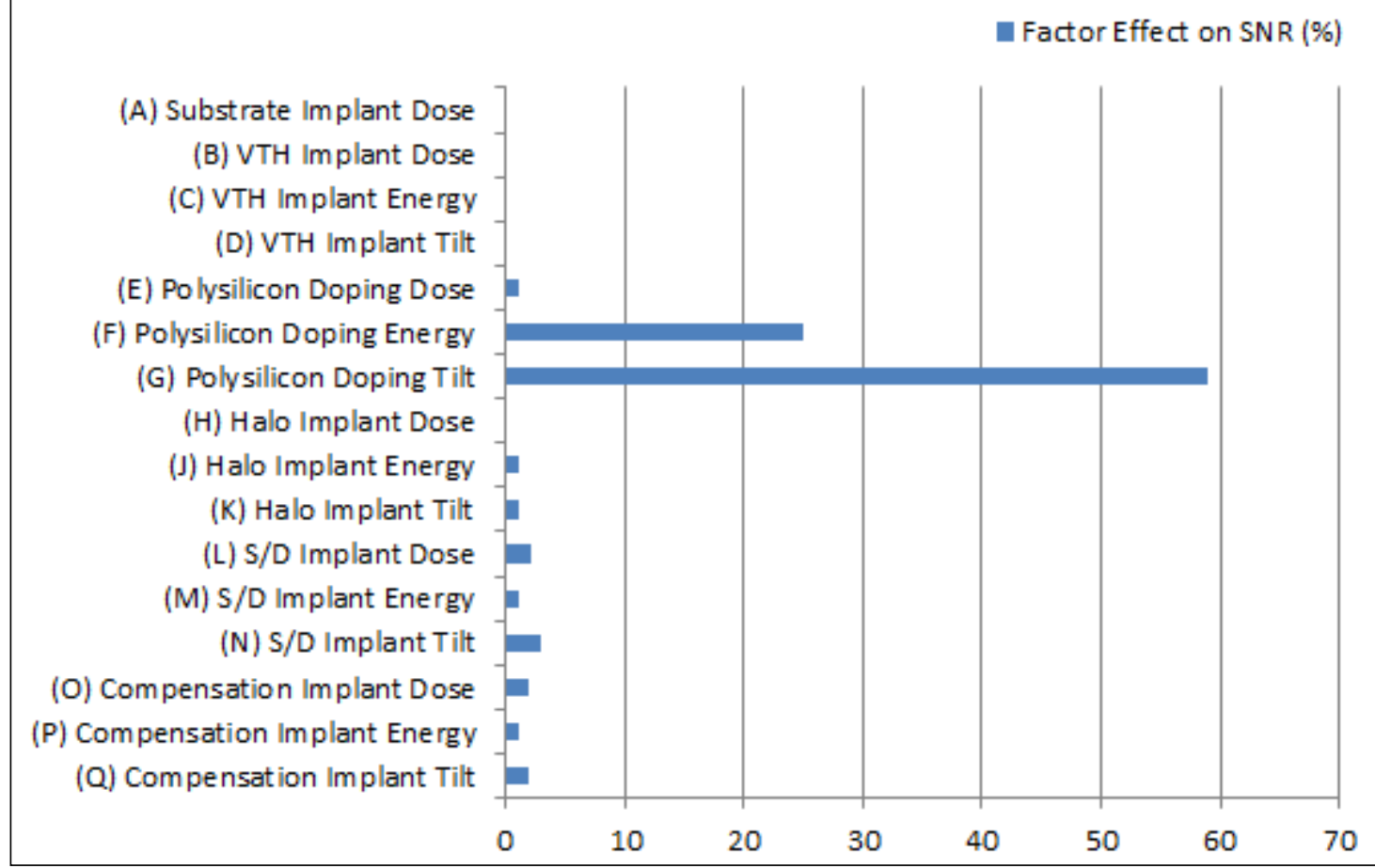

Figure 3. Pareto plot of $\mathrm{I}_{\mathrm{OFF}}$ for SOI vertical DG-MOSFET sevice.

From Figure 3, it is obvious that output response $\mathrm{I}_{\mathrm{OFF}}$, factor $\mathrm{G}$ (Polysilicon doping tilt $=59 \%$ ) and factor $\mathrm{F}$ (Polysilicon doping energy $=25 \%$ ) were the most significant parameters. Since the factor $G$ and factor $F$ were fixed to level 1, the other input process parameters were varied in order to get an optimum result. After a few adjustments were made on the level of process parameters, the best level setting of process parameters was 
identified as A1, B2, C2, D2, E1, F1, G1, H1, J2, K1, L1, M3, N1, O1, P1 and Q3. Factor A, B, C, D, E, F, G, H, J, K, L, M, N, O, P and Q each represents substrate implant dose, $\mathrm{V}_{\mathrm{TH}}$ implant dose, $\mathrm{V}_{\mathrm{TH}}$ implant energy, $\mathrm{V}_{\mathrm{TH}}$ implant tilt, polysilicon doping dose, polysilicon doping energy, polysilicon doping tilt, halo implant dose, halo implant energy, halo implant tilt, S/D implant dose, S/D implant energy, S/D implant tilt, compensation implant dose, compensation implant energy and compensation implant tilt respectively.

\section{Confirmation Experiment for Response, IoFF}

The confirmation experiment is used to verify the expected results with the experimental results. The best setting of input process parameters for SOI Vertical DG-MOSFET device which were suggested by Taguchi method is shown in Table 8 . The confirmation experiment is required in the device design because the optimum combination of parameters and their levels, i.e. A1, B2, C2, D2, E1, F1, G1, H1, J2, K1, L1, M3, N1, O1, P1 and Q3 do not correspond to any experiment of the orthogonal array.

Table 8 . Best setting of process parameters.

\begin{tabular}{lccc}
\hline Symbol & Process Parameter & Units & Best Value \\
\hline A & Substrate Implant Dose & atom $/ \mathrm{cm}^{3}$ & $1 \times 10^{14}$ \\
B & $\mathrm{V}_{\text {TH Implant Dose }}$ & atom $/ \mathrm{cm}^{3}$ & $3.81 \times 10^{11}$ \\
C & $\mathrm{V}_{\text {TH Implant Energy }}$ & $\mathrm{kev}$ & 12 \\
$\mathrm{D}$ & $\mathrm{V}_{\mathrm{TH}}$ Implant Tilt & $\mathrm{degree}$ & 10 \\
$\mathrm{E}$ & Polysilicon Doping Dose & atom $/ \mathrm{cm}^{3}$ & $3.60 \times 10^{14}$ \\
$\mathrm{~F}$ & Polysilicon Doping Energy & $\mathrm{kev}$ & 20 \\
$\mathrm{G}$ & Polysilicon Doping Tilt & $\mathrm{degree}$ & 7 \\
$\mathrm{H}$ & Halo Implant Dose & atom $/ \mathrm{cm}^{3}$ & $1.17 \times 10^{13}$ \\
$\mathrm{~J}$ & Halo Implant Energy & $\mathrm{kev}$ & 172 \\
$\mathrm{~K}$ & Halo Implant Tilt & $\mathrm{degree}$ & 24 \\
$\mathrm{~L}$ & S/D Implant Dose & atom $/ \mathrm{cm}^{3}$ & $1.22 \times 10^{18}$ \\
$\mathrm{M}$ & S/D Implant Energy & $\mathrm{kev}$ & 47 \\
$\mathrm{~N}$ & S/D Implant Tilt & $\mathrm{degree}$ & 74 \\
$\mathrm{O}$ & Compensation Implant Dose & atom $/ \mathrm{cm}^{3}$ & $2.51 \times 10^{12}$ \\
P & Compensation Implant Energy & $\mathrm{kev}$ & 61 \\
$\mathrm{Q}$ & Compensation Implant Tilt & $\mathrm{degree}$ & 13 \\
\hline
\end{tabular}

The result of the final simulation for the device is shown in Table 9. Before the optimization approaches, the best SNR (Lower-the-better) is $37.393 \mathrm{~dB}$ at row of experiment no. 24 (refer to Table 5). After the optimization approaches, the SNR (Lowerthe-better) of leakage current (IofF) for SOI Vertical DG-MOSFET device is $39.44 \mathrm{~dB}$, which is higher than any values in Table 5. Hence, it is proven that the selected level of input process parameters are the optimum level setting (The highest SNR). In addition, these values are still within the predicted range. For $\mathrm{S} / \mathrm{N}$ ratio (Lower-the-better), 39.44 $\mathrm{dB}$ is within predicted range $\mathrm{S} / \mathrm{N}$ ratio of 19.73 to $59.15 \mathrm{~dB}(39.44 \pm 19.71 \mathrm{~dB})$. These indicate that Taguchi method is able to predict the optimum solution in finding the SOI Vertical DG-MOSFET device fabrication recipe with lowest leakage current value. The leakage current (I I $\mathrm{OFF}$ ) value for the device after was observed to be $0.009 \mathrm{nA} / \mu \mathrm{m}$ or 9 $\rho \mathrm{A} / \mu \mathrm{m}$ as highlighted in Table 9 . This leakage current (IOFF) value was observed to be the lowest value among all the experiments done before. 
Table 9. Results of confirmation experiments for IOFF

\begin{tabular}{|c|c|c|c|c|}
\hline \multicolumn{4}{|c|}{ Leakage Current, IofF $(\mathrm{nA} / \mu \mathrm{m})$} & \multirow[t]{2}{*}{ SNR (Lower-the-better) } \\
\hline $\begin{array}{c}\text { IOFF1 } \\
\left(\mathrm{U}_{1} \mathrm{~V}_{1}\right)\end{array}$ & $\begin{array}{c}\text { IoFF2 } \\
\left(\mathrm{U}_{1} \mathrm{~V}_{2}\right)\end{array}$ & $\begin{array}{c}\text { IOFF3 } \\
\left(\mathrm{U}_{2} \mathrm{~V}_{1}\right)\end{array}$ & $\begin{array}{c}\text { IoFF4 } \\
\left(\mathrm{U}_{2} \mathrm{~V}_{2}\right)\end{array}$ & \\
\hline 0.016 & 0.012 & 0.013 & 0.009 & 39.44 \\
\hline
\end{tabular}

\section{CONCLUSIONS}

In conclusion, the optimum solution in designing SOI Vertical DG-MOSFET device with lowest leakage current ( $\mathrm{I}_{\mathrm{OFF}}$ ) value was successfully predicted by utilizing $\mathrm{L}_{36}$ orthogonal array [2] of Taguchi method. Leakage current (IOFF) is the main response studied in this project as it is one of the main factors that affect the power consumption of the device. Leakage current ( $\mathrm{I}_{\mathrm{OFF}}$ ) must be as low as possible while keeping the drive current ( $\mathrm{I}_{\mathrm{ON}}$ ) value at a high level. This will result in higher $\mathrm{I}_{\mathrm{ON}} / \mathrm{I}_{\mathrm{OFF}}$ ratio, thereby lowering the power consumption of the device. Taguchi method design is used to develop a systematic design of experiment. It has many variants that can be applied to model the device and a lot of input process parameters can be analyzed. The level of significance of each input process parameters on leakage current (IOFF) is determined by using ANOVA. Based on the ANOVA method, the most dominant input process parameters on leakage current (IOFF) were factor $G$ (Polysilicon doping tilt $=59 \%$ ) and factor $F$ (Polysilicon doping energy $=25 \%$ ). The leakage current ( $\mathrm{I}_{\mathrm{OFF}}$ ) value after the optimization approach was 0.009 $\mathrm{nA} / \mu \mathrm{m}$ or $9 \rho \mathrm{A} / \mu \mathrm{m}$ while keeping the drive current (ION) value at $434 \mu \mathrm{A} / \mu \mathrm{m}$. Both the drive current ( $\left.\mathrm{I}_{\mathrm{ON}}\right)$ and leakage current (I $\left.\mathrm{I}_{\mathrm{OFF}}\right)$ values yield a higher $\mathrm{I}_{\mathrm{ON}} / \mathrm{I}_{\mathrm{OFF}}$ ratio $(48.22 \mathrm{x}$ $10^{6}$ ) for lower power consumption application.

\section{ACKNOWLEDGEMENTS}

The authors would like to thank the Ministry of Higher Education (MOHE) and Centre for Telecommunication Research and Innovation (CeTRI), Faculty of Electronics and Computer Engineering (FKEKK), Universiti Teknikal Malaysia Melaka (UTeM) for sponsoring this research study under the research grants (PJP/2014/FKEKK(6B)/S01341) and FRGS(RACE)/2012/FKEKK/TK02/02/2 F00148.

\section{REFERENCES}

[1] Kassim DH, Putra A, Nor MJM, Muhammad NS. Effect of pyramidal dome geometry on the acoustical characteristics in a mosque. Journal of Mechanical Engineering and Sciences. 2014;7:1127-33.

[2] Joardder MUH, Karim A, Kumar C. Effect of temperature distribution on predicting quality of microwave dehydrated food. Journal of Mechanical Engineering and Sciences. 2013;5:562-8.

[3] Yadav VK, Rana AK. Impact of channel doping on DG-MOSFET parameters in nano regime-TCAD simulation. International Journal of Computer Applications. 2012;37:36-41.

[4] K. Roy SM, H. M. Meimand. leakage current mechanisms and leakage reduction techniques in deep-submicrometer CMOS circuits. Proceedings of the IEEE. 2003;91:305-27. 
[5] Mead C. Scaling of MOS technology to submicrometer feature sizes. Analog Integrated Circuits Signal Process. 1994;6:9-25.

[6] Sivananth V, Vijayarangan S. Fatigue life analysis and optimization of a passenger car steering knuckle under operating conditions. International Journal of Automotive and Mechanical Engineering. 2015;11:2417-29.

[7] Shukri MR, Rahman MM, Ramasamy D, Kadirgama K. Artificial neural network optimization modeling on engine performance of diesel engine using biodiesel fuel. International Journal of Automotive and Mechanical Engineering. 2015;11:2332-47.

[8] Meenu, Kumar S. Optimization of the material removal rate in turning of UDGFRP using the particle swarm optimization technique. International Journal of Automotive and Mechanical Engineering. 2013;8:1226-41.

[9] Chaki S, Ghosal S. A GA-ANN hybrid model for prediction and optimization of $\mathrm{CO}_{2}$ laser-mig hybrid welding process. International Journal of Automotive and Mechanical Engineering. 2015;11:2458-70.

[10] Esme U. Application of Taguchi method for the optimization of resistance spot welding process. The Arabian Journal for Sciences and Engineering. 2009;30.

[11] Salehuddin F, Ahmad I, Hamid FA, Zaharim A, Elgomati HA, Majlis BY, Apte PR. Optimization of HALO structure effects in 45nm p-type MOSFETs device using Taguchi method. World Academy of Science, Engineering and Technology. 2011;51:1136-42.

[12] Naidu NVR. Mathematical model for quality cost optimization. Proc International Conference on Flexible Automation and Intelligent Manufacturing. 2008. p. 811-5.

[13] Supeni EE, Epaarachchi JA, Islam MM, Lau KT. Development of artificial neural network model in predicting performance of the smart wind turbine blade. Journal of Mechanical Engineering and Sciences. 2014;6:734-45.

[14] Abdullah H, Jurait J, Lennie A, Nopiah ZM, Ahmad I. Simulation of fabrication process VDMOSFET transistor using silvaco software. European Journal of Scientific Research. 2009;29:461-70.

[15] Yang K, Teo EC, Fuss FK. Application of Taguchi method in optimization of cervical ring cage. International journal of Biomechanics. 2007;40:3251-6.

[16] Tangjitsitcharoen S, Nunya N. Reduction of oil contamination on hard disk drive parts using automatic hydrocarbon washing machine. Journal of Mechanical Engineering and Sciences. 2011;1:113-23.

[17] Kaharudin KE, Hamidon AH, Salehuddin F. Impact of height of silicon pillar on vertical DG-MOSFET device. International Journal of Computer, Information, Systems and Control Engineering. 2014;8:576-80.

[18] Elgomati HA, Ahmad I, Salehuddin F, Hamid FA, Zaharim A, Majlis BY, Apte PR. Optimal solution in producing $32 \mathrm{~nm}$ cmos technology transistor with desired leakage current. International Journal Semiconductor Physics Quantum Electron Optoelectron. 2011;14:145-51.

[19] Najiha MS, Rahman MM, Yusoff AR. Modeling of the end milling process for aluminum alloy AA6061 T6 using HSS tool. International Journal of Automotive and Mechanical Engineering. 2013;8:1140-50.

[20] Haniff MHM, Ismail AR, Deros BM, Rahman MNA, Kardigama K. The Taguchi approach in optimizing the environmental factors towards productivity at automotive industry. International Journal of Automotive and Mechanical Engineering. 2011;3:306-17. 
[21] Belavendram N. Application of genetic algorithms for robust parameter optimization. International Journal of Automotive and Mechanical Engineering. 2010;2:211-20.

[22] Phadke MS. Quality engineering using robust design: Pearson Education, Inc. and Dorling Kindersley Publishing, Inc; 2001.

[23] Beale S, Spalding D. Numerical study of fluid flow and heat transfer in tube banks with stream-wise periodic boundary conditions. Transactions of the CSME. 1998;22:397-416. 